\title{
The Effect of Breastfeeding on The Uterine Involution Post Partum Mothers
}

\author{
Rini Amelia, Masrul, Roza Sriyanti
}

\begin{abstract}
Background: The aim of the study determine the effect of breastfeeding on the uterine involution post partum mothers. Methods: The study was conducted using a cohort design. The study was conducted at Independent Midwives of Padang Panjang City, West Sumatera Province, Indonesia from November to December 2017. The population in this study was spontaneous postpartum mother treated at Independent Midwives who did and did not initiate early breastfeeding within 1 hour after baby born and followed by breastfeeding babies with breast milk for 7 days with a sample size of 42 people in two groups. Sampling technique with consecutive sampling. Measurement of fundal height using caliper pelvimetry. Test the normality of data by Shapiro-Wilk test and hypothesis test using paired t test. A two-tailed $P$-value of $<0.05$ was considered statistically significant. Results: The result of statistical test of independent $T$ test was obtained $p=0,000$ (p value $<0,05)$ it can be concluded that there is difference of fundal height day 1,3 and 7 in breastfeeding and non-breastfeeding group. The result of this research can be concluded that there is the effect of breastfeeding mother to postpartum uterine involution ( $p$ value $<0.05$ ) Conclusion: The conclusion of this study confirmed there was an effect of breastfeeding on the uterine involution post partum mothers.
\end{abstract}

Index Terms - breastfeeding, uterine involution, post partum

\section{INTRODUCTION}

Data from Ministry of Health Republic of Indonesia complicating puerperium is one of the causes of maternal death by $8 \%$ [1]. Activities that are of concern in the postpartum period are the administration of early initiation of breastfeeding within 1 hour after birth and ensuring uterine involution runs normally. Early initiation of breastfeeding is a process of breastfeeding the baby immediately after birth for 1 hour. Early initiation of breastfeeding is one of the factors that affect uterine involution because stimulation occurs when breastfeeding and the release of hormones include oxytocin which functions in addition to stimulating contractions of the smooth muscles of the breast, also causing contraction and retraction of the uterine muscles. This will suppress blood vessels which result in reduced blood supply to the uterine. This process helps to reduce the site or place of implantation of the placenta and reduce bleeding [2]. Mothers who initiate early breastfeeding will accelerate uterine involution due to

Rini Amelia Master of Midwifery Program, Faculty of Medicine Universitas Andalas, Padang City, Indonesia

Masrul, Department of Nutrition, Faculty of Medicine Universitas Andalas, Padang City, Indonesia.

Roza Sriyanti, Department of Obstetric and Gynaecology, Faculty of Medicine Universitas Andalas, Padang City, Indonesia. the influence of the oxytocin hormone which can increase uterine contractions [3].

The risk of postpartum complications is 3.5 times higher in women who do not initiate early breastfeeding in the first 24 hours of labor and are reduced by 7 days after giving birth other than that the risk of neonatal death is four times higher in children given other than breast milk [4].

The coverage of exclusive breastfeeding in the world is seen by region, known to reach $25 \%$ in Central Africa, $32 \%$ in Latin America and 30\% in East Asia, 47\% in South Asia, and $46 \%$ in developing countries. Overall, less than 40 percent of children under the age of six are given exclusive breastfeeding [5]. While coverage of early breastfeeding initiation practices in the world was $42 \%$ in the period 2010-2015. The prevalence of early breastfeeding initiation in Indonesia is still lower at 49.3\% [1]. In 2013 there was a decrease in the percentage of mothers who carried out early breastfeeding initiation at $34.5 \%$ [1]. This figure is still very low when compared to other countries in Southeast Asian countries such as Myanmar (76\%), Thailand (50\%), and the Philippines (54\%) [5,6].

The aim of the study determine the effect of breastfeeding on the uterine involution post partum mothers.

\section{MATERIALS AND METHODS}

\section{A. Study Design and Research Sample}

The study was conducted using a cohort design. The study was conducted at Independent Midwives of Padang Panjang City, West Sumatera Province, Indonesia from November to December 2017. The population in this study was spontaneous postpartum mother treated at Independent Midwives who did and did not initiate early breastfeeding within 1 hour after baby born and followed by breastfeeding babies with breast milk for 7 days with a sample size of 42 people in two groups. Sampling technique with consecutive sampling.

\section{B. Operational Definitions}

The variables of this study included independent variable is breastfeeding and dependent variable is uterine involution post partum mothers.

\section{Data Collection Technique}

This study was approved by the Ethical Committee of Medical Faculty, Universitas Andalas with registration number 511/KEP/FK/2017. Early initiation of breastfeeding within 1 hour after baby born and followed by breastfeeding babies with breast milk for 7 days. Measurement of fundal height using caliper pelvimetry with procedures after early 


\section{Correlation of Fat Consumption and Lipid Profile for Telomere Length of Minangkabau Ethnicity Men, in West Sumatera, Indonesia}

initiation of breastfeeding,. Measurements of fundal height were carried out by researchers assisted by accompanying researchers (midwives). To avoid the occurrence of bias in measuring the height of the uterine fundus, it was carried out by 2 people, namely the researcher and the accompanying researcher who conducted it simultaneously. If there are differences in measurements $>20 \%$, the measurement of fundal heigh is repeated.

\section{Data Analysis}

The quantitative variables were recorded as Mean \pm SD, median and percentage. Test the normality of data by Shapiro-Wilk test and hypothesis test using paired t test. A two-tailed $P$-value of $<0.05$ was considered statistically significant. A two-tailed $P$-value of $<0.05$ was considered statistically significant. Data were analyzed using the Stata version 14.2 (Stata Corporation).

\section{RESULTS}

Characteristics of respondents (Table 1).

Table 1: Characteristics of respondents

\begin{tabular}{lcc}
\hline Characteristics & $\begin{array}{c}\text { Breastfeeding } \\
(\mathbf{n = 2 1})\end{array}$ & $\begin{array}{c}\text { Not Breastfeeding } \\
(\mathbf{n = 2 1})\end{array}$ \\
\hline Age (years) & $28.33 \pm 4.12$ & $27.52 \pm 3.87$ \\
Parity & $2.24 \pm 0.70$ & $2.10 \pm 1.09$ \\
\hline
\end{tabular}

Table 1 showed age of respondents in breastfeeding group $28.33 \pm 4.12$ years and $27.52 \pm 3.87$ in not breastfeeding group. Parity of breastfeeding group $2.24 \pm 0.70$ and $2.10 \pm$ 1.09 in not breastfeeding group.

Table 2: Mean difference of fundal height between breastfeeding and not breasfeeding group

\begin{tabular}{cccc}
\hline & \multicolumn{2}{c}{ Group } & \\
\cline { 2 - 3 } Fundal & $\begin{array}{c}\text { Breastfeeding } \\
\text { (Mean } \pm \text { SD) }\end{array}$ & $\begin{array}{c}\text { Not } \\
\text { Breastfeeding } \\
\text { Height }\end{array}$ & $\begin{array}{c}\text { p } \\
\text { value }\end{array}$ \\
\hline Day 1 $(\mathrm{cm})$ & $10.76 \pm 1,06$ & $13.46 \pm 0,97$ & 0.000 \\
Day 3 $(\mathrm{cm})$ & $8.55 \pm 0,91$ & $11.64 \pm 0,64$ & 0.000 \\
Day 7 $(\mathrm{cm})$ & $4.28 \pm 0,53$ & $7.64 \pm 0,78$ & 0.000 \\
$\Delta$ Day 1-3 & 2.21 & 1.82 & 0.001 \\
$\Delta$ Day 3-7 & 4.27 & 4.00 & 0.005 \\
$\Delta$ Day 1-7 & 6.48 & 5.82 & 0.001 \\
\hline
\end{tabular}

Table 2 showed the mean fundal height the breastfeeding group was found to decline on days 1, 3 and 7 . The decrease in fundal height on days $1-3$ is $2.21 \mathrm{~cm}$ and on days $3-7$ is $4.27 \mathrm{~cm}$. While on days $1-7$ there are $6.47 \mathrm{~cm}$. The mean fundal height in the non-breastfeeding group on days 1-3 is $1.82 \mathrm{~cm}$ and on days $3-7$ is $4 \mathrm{~cm}$ whereas on day $1-7$ is 5.82 $\mathrm{cm}$. There is mean difference of fundal height between breastfeeding and not breasfeeding group $(\mathrm{p}<0.05)$.
Table 3: The effect of breastfeeding on the uterine involution post partum mothers

\begin{tabular}{|c|c|c|c|}
\hline $\begin{array}{c}\text { Uterine } \\
\text { Involution } \\
\end{array}$ & Mean \pm SD & $\Delta$ Mean & $p$ Value \\
\hline $\begin{array}{l}\text { Day } 1(\mathrm{~cm}) \\
\text { Day } 3(\mathrm{~cm})\end{array}$ & $\begin{array}{c}10.76 \pm 1.06 \\
8.55 \pm 0.91\end{array}$ & 2.21 & $0.000^{*}$ \\
\hline $\begin{array}{l}\text { Day } 1(\mathrm{~cm}) \\
\text { Day } 7(\mathrm{~cm})\end{array}$ & $\begin{array}{c}10.76 \pm 1.06 \\
4.28 \pm 0.53\end{array}$ & 6.48 & $0.000^{*}$ \\
\hline
\end{tabular}

Table 3 showed fundal height of uterine involution on day $1-3$ is $2.21 \mathrm{~cm}$ and day $1-7$ is $6.48 \mathrm{~cm}$. There was statistically significant breastfeeding on the uterine involution post partum mothers $(\mathrm{p}<0.05)$.

\section{Estimated Marginal Means of MEASURE_1}

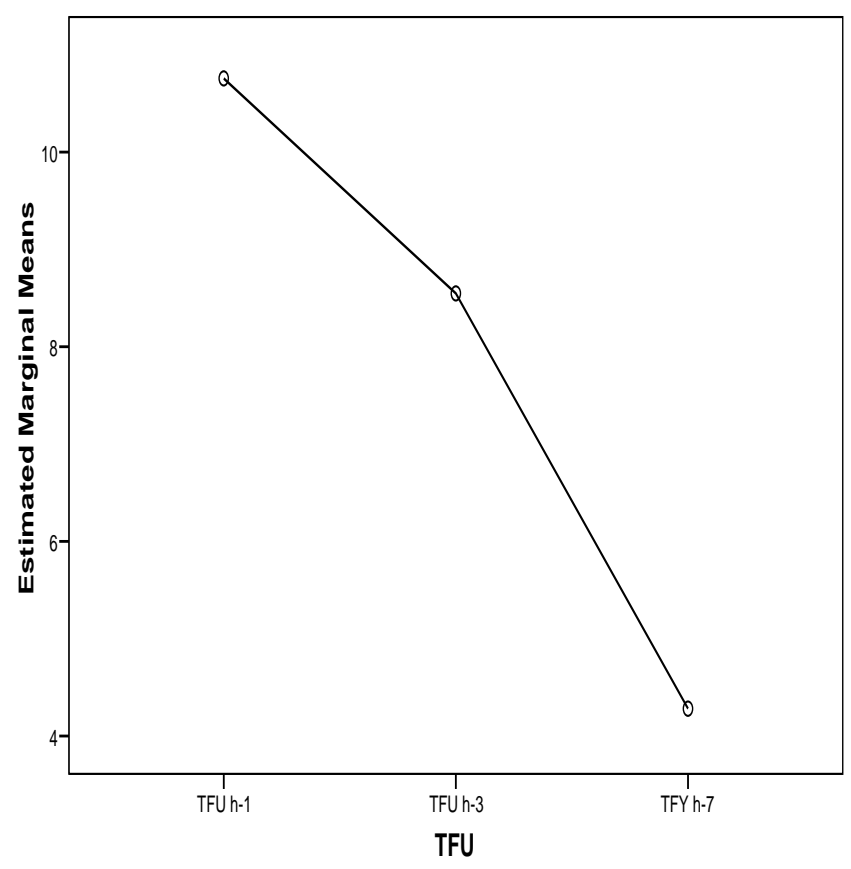

Figure 1: Mean of fundal height on breastfeeding mothers

Figure 1 showed there was a decrease in the mean of fundal on breastfeeding mothers who breastfeeding on day $1-7$.

\section{DISCUSSION}

The result showed there was an effect of breastfeeding on the uterine involution post partum mothers. The fundal height reduction process is fast if on the first day of the fundal height $>1$ finger naked below the center and on the 3rd day $>3$ fingers below the center. It is said to be normal if on the first day fundal height 1 finger is below the center, and on the $3 \mathrm{rd}$ day fundal height 3 fingers below the center. But it is said to be slow if on first day fundal height $<1$ finger below the center, and on the 3rd day fundal height $<3$ finger below the center. In this study, fundal height decrease in breastfeeding mothers found a decrease in fundal height on days 1 and 3 of 2.21 and was in the fast category and until day 7 there was a decrease of $6.48 \mathrm{~cm}$. 
Previous studies known early breastfeeding has an effect on uterine involution [3]. Another study there is a relationship between early breastfeeding initiation and an increase in postpartum maternal recovery (p value <0.05) [8].

Giving breast milk or breastfeeding should be done immediately after the newborn baby, this can foster a relationship or bond between mother and baby and can provide a warm feeling by laying and attaching to the mother's skin and covering it, breastfeeding is maximum because this is very important whether the baby will get enough milk or not. This is realized by the role of the milk-making hormone, including the hormone prolactin in the blood circulation of the mother will decrease after one hour of labor caused by the release of the placenta. In an effort to maintain prolactin, baby suction will provide stimulation to the pituitary to expel the oxytocin hormone. The oxytocin hormone works to stimulate smooth muscle to squeeze the milk that is in the alveoli, lobes and ducts containing breast milk released through the nipple [7,8].

In this condition the baby's suction will help expel the milk. The process is when the baby sucks the smooth muscles of the nipple aroused, this stimulation by the nerve is transmitted to the brain. Then the brain instructs the back of the pituitary gland to expel the oxytocin hormone which is carried to the smooth muscles of the breast, so that the smooth muscles of the breast contract. With the contraction of these smooth muscles the milk is released, and in the cell occurs breastfeeding production again. The oxytocin hormone not only affects the smooth muscles of the breasts but also the smooth muscles of the uterus so that the uterus contracts better, thus involution of the uterus faster and lochea's expenditure more smoothly. That is why in mothers who breastfeed involution of the uterus lasts faster than not breastfeeding $[9,10]$.

Based on the phenomenon that the researchers met in the field there are factors that support and inhibit exclusive breastfeeding. Supporting factors include the mother's support from health workers and families, especially in this case is husband. While the inhibiting factors include the mistaken perception of the mother that she feels she has not yet existed, the mother assumes that the new baby will be breastfed if she and her baby are clean (bathing), and the mother feels exhausted after the labor process and is just going to breastfeed if the condition is right completely recovered. In addition, the researchers also found a lack of cooperation between mother and family and health workers who helped deliver. If seen of course, every medical action still needs approval from the family, before exclusive breastfeeding is carried out, it still needs to be consulted with the family about the benefits and importance of breastfeeding, but the researchers found several conditions where the family refused advice from officers to carry out exclusive breastfeeding, so the officers could not force implementing exclusive breastfeeding for babies.

Implementation of early breastfeeding as possible by putting the baby on the mother's breast will benefit the mother and baby. Stroke baby's head on mother's breast, touch baby's hand when breastfeeding, baby on mother's nipple will stimulate expulsion of hormone oxytocin which will support to uterine contractions and accelerate the process of uterine involution.

\section{CONCLUSION}

The conclusion of this study confirmed there was an effect of breastfeeding on the uterine involution post partum mothers.

\section{ACKNOWLEDGMENT}

We would like to thank all respondents who participated in this study.

\section{REFERENCES}

[1] Ministry of Health Republic of Indonesia. Overview of maternal health in Indonesia. Data and Information Center, Jakarta, 2013.

[2] Dieterich CM, Felice JP, O'Sullivan E, Rasmussen KM Breastfeeding and Health Outcomes for the Mother-Infant Dyad. Pediatr Clin North Am. 2013; 60: 31-48.

[3] Kristoschek JH, Moreira de Sa RA, Silva FCD, Vellarde GC. Ultrasonographic Evaluation of Uterine Involution in the Early Puerperium. Rev Bras Ginecol Obstet. 2017; 39:149-154.

[4] Edmond KM, Zandoh C, Quigley MA, Amenga-Etego S, Owusu-Agyei S, Kirkwood BR. Delayed breastfeeding initiation increases risk of neonatal mortality. Pediatrics. 2006; 117:e380-6.

[5] World Health Organization. Medical Record Manual A Guide For Developing Countries. World Health Organization, Geneva, 2015

[6] NindreaRD, Aryandono T, Lazuardi L, Dwiprahasto I. Diagnostic accuracy of different machine learning algorithms for breast cancer risk calculation: A meta-analysis. Asian Pac J Cancer Prev. 2018; 19: 174-52.

[7] Fuchs A-R, Romero R. Oxytocin secretion and human parturition: fulse frequency and duration increase during spontaneous labor. American Journal of Obstetrics and Gynaecology. 2001; 165: 1515-23.

[8] Mc.Govern P, Dowd B, Gjerdingen D, Gross CR, Kenney S, Ukestad L et al. Postpartum Health of Employed Mothers 5 Weeks After Childbirth. Ann Fam Med. 2006; 4: 159-167

[9] Dieterich CM, Felice JP, O'Sullivan E, Rasmussen KM. Breastfeeding and Health Outcomes for the Mother-Infant Dyad. Pediatr Clin North Am. 2012; 60: 31-48.

[10] Harahap WA, Sudji IR, Nindrea RD. BRCA1 promoter methylation and clinicopathological characteristics in sporadic breast cancer patients in Indonesia. Asian Pac J Cancer Prev. 2018; 19: 2643-9. 